\title{
DE AMARILDO AO HAITI: REFLEXÕES SOBRE UNIVERSALIDADE E MEMÓRIA EM TORNO DE DUAS HASHTAGS
}

\author{
DEBORAH PEREIRA ${ }^{1}$ \\ Laboratório de Estudos Urbanos (LABEURB) \\ Universidade Estadual de Campinas \\ Rua Caio Graco Prado, 70 - Cidade Universitária, Barão Geraldo, SP, 13083-970. \\ deborah.p16@gmail.com
}

Resumo. Este trabalho objetiva compreender, à luz da Análise de Discurso, como opera a hashtag \#SomosTodos(Amarildo, Maju, etc.). Partindo de \#SomosTodosAmarildo, a reflexão empreendida aborda o funcionamento das hashtags sob a ordem da circulação de sentidos (ORLANDI, 2001) e as relaciona com a noção de arquivo (PÊCHEUX, 1981). Além disso, o artigo propõe pensar a hashtag em análise sob a perspectiva da Universalidade colocada também por Pêcheux $(1975,1982)$, discutindo o caráter homogêneo de sua estrutura - que é ressignificado através da Memória (COURTINE, 1981) por outro acontecimento discursivo: \#NinguémÉHaiti. Assim, as noções de efeito metafórico (PÊCHEUX, 1990) e sentidos em fuga (ORLANDI, 2012) também são mobilizadas e permitem refletir sobre um encontro entre Amarildo e Haiti.

Palavras-chave: hashtag; deriva; memória; universalidade.

\begin{abstract}
This paper aims to understand, in the light of Discourse Analysis, how the hashtag \#SomosTodos (Amarildo, Maju, etc.) operates. Starting from \#SomosTodosAmarildo, the reflection undertaken deals with the operation of hashtags under the order of the circulation of meanings (ORLANDI, 2001) and relates them to the notion of archive (PECCHEUX, 1981). In addition, the article proposes to think of the hashtag in analysis from the perspective of Universality also posed by Pêcheux (1975, 1982), discussing the homogenous character of its structure - which is re-signified through Memory (COURTINE, 1981) by another discursive event: \#NinguémÉHaiti. Thus, the notions of metaphorical effect (PECHEUX, 1990) and meanings on the run (ORLANDI, 2012) are also mobilized and allows reflecting on a meeting between Amarildo and Haiti.
\end{abstract}

Palavras-chave: hashatg; drift; memory; universality.

\footnotetext{
${ }^{1}$ Mestranda do Programa de Divulgação Científica e Cultural (LABJOR/UNICAMP).
} 
O Haiti é aqui

O Haiti não é aqui

Caetano Veloso

\section{PALAVRAS INICIAIS}

Em julho de 2013, o ajudante de pedreiro Amarildo de Souza foi executado pela polícia militar na Favela da Rocinha, no Rio de Janeiro e, desde então, não se obteve notícias a seu respeito. O desaparecimento de Amarildo tornou-se símbolo da luta contra a violência e abuso policial, gerando uma campanha de comoção nacional que tinha como objetivo arrecadar dinheiro e dar suporte tanto para a família de Amarildo quanto para outras famílias que passaram por situações semelhantes,gerando o dizer "Somos Todos Amarildo". Logo, a estrutura tomou forma de hashtag (\#SomosTodosAmarildo) e foi (re) compartilhada não apenas nas redes sociais, mas também em shows, eventos diversos, manifestações nas ruas, muros de vias públicas, etc. \#SomosTodosAmarildo tornou-se um grande projeto - o qual contou com a produção de vídeos, shows, leilões de obras de arte e jantares beneficientes -que visava denunciar a opressão policial, traçar um perfil das vítimas e preservar a memória dos desaparecidos na região metropolitana do Rio de Janeiro, buscando refletir a respeito da segurança pública, racismo, corrupção policial etc.

A partir deste acontecimento, outras hashtags com a estrutura '\# $\underline{\text { Somos Todos' }}$ emergiram nas redes: \#SomosTodosMacacos, \#SomosTodosMaju, \#SomosTodosCharlieHebdo, \#SomosTodosProfessores são alguns exemplos. Todas traziam em comum i) uma vontade de protesto em relação a alguma situação considerada injusta ou preconceituosa; ii) uma tentativa de apoio a alguém ou algo que teria sido vítima desta situação. Mais tarde, foi possível notar que a hashtag começou a ser utilizada em campanhas publicitárias ou para promoção de torcidas a candidatos de reality shows diversos. Durante as olimpíadas de 2016, por exemplo, \#SomosTodosBrasil e \#SomosTodosOlímpicos foram bastante recompartilhadas; a primeira fez parte de uma propaganda promovida pelo governo federal e a segunda pela Rede Globo de Televisão.

É curioso observar que nenhuma das campanhas posteriores ao \#SomosTodosAmarildo, que utilizam desta mesma estrutura, diz respeito a moradores da periferia que foram executados injustamente pela polícia (pelo menos das que tiveram grande repercussão nas redes). Mas, desde 2013, o número de pessoas mortas por policiais vem subindo significativamente, especialmente em territórios de favela e periferia, de acordo com o diretor da Anistia Internacional no Brasil em entrevista ao site Huffpost Brasil $^{2}$. Ou seja, a hashtag \#SomosTodos, a partir da campanha de Amarildo, derivou para outros usos, movimentando seus sentidos já que "um enunciado é intrinsecamente suscetível de tornar-se outro, diferente de si mesmo, de deslocar-se discursivamente de seu sentido para derivar para um outro" (PÊCHEUX 1983[1990, p. 53]). O sentido de denúncia (ao abuso policial, ao descaso do Estado e ao racismo institucionalizado) a partir de \#SomosTodosAmarildo foi se esvaziando e deslocando-se, passando a funcionar como um gesto de torcida, apoio ou protesto a causas diversas. ${ }^{3}$

\footnotetext{
${ }^{2}$ Notícia do site HuffPost Brasil. Disponível em: http://www.brasilpost.com.br/2016/04/05/violenciapolicial-mare n $9618778 . h \mathrm{html}$. Acessado em: 10 de dezembro de 2016.

${ }^{3}$ No quarto tópico deste artigo, os deslocamentos de sentido da hashtag\#SomosTodosAmarildo, bem como seu esvaziamento, serão melhor esmiuçados.
} 
Assim, à luz destas questões e das teorias de Análise de Discurso, este trabalho propõe pensar o funcionamento da hashtag \#SomosTodos e suas relações com \#NinguémÉHaiti, que surge na relação com o outro acontecimento discursivo e funciona pelo avesso deste desejo de "ser todos".

\section{FUNCIONAMENTO DA HASHTAG E SUA CIRCULAÇÃO}

\subsection{FUNCIONAMENTO DA HASHTAG}

As hashtags são amplamente utilizadas em diferentes mídias digitais. Elas surgiram no Twitter como uma tentativa de atender a necessidade que os usuários tinham de estabelecer trocas de informações entre si. Chris Messina $(2007)^{4}$, um dos criadores do site e da hashtag explica que, no momento em que é reunido o símbolo \# (has) a uma palavra-etiqueta (tag), este canal de troca entre os usuários é criado.

Paveau (2013) define a hashtag como um segmento linguageiro precedido pelo sinal \# - que a torna clicável e possibilita a criação de um fio. São, assim, "tecnopalavras clicáveis [...] que permitem a organização da informação pela reunião de várias mensagens[...]" (PAVEAU, 2013, s.p.; tradução minha) $)^{5}$.

É importante registrar que as hashtags já ultrapassam o uso nas redes, sendo notadas também em ambientes 'não-clicáveis' como em muros de vias públicas, camisetas, cartazes, programas televisivos e até mesmo em enunciações orais. Nas palavras de Paveau,

encontramos as hashtags em um e-mail ou um texto, ou em alguns sites, nos quais eles são integrados linguisticamente nos enunciados, sem sua função hipertextual. Notamos que a forma migrou para contextos em que ela não funciona como uma tecnopalavra; ela possui, portanto, outra função, que será preciso determinar. (PAVEAU, 2013, s.p.; tradução minha) ${ }^{6}$

Ao circular em meios não clicáveis, a hashtag deixa de funcionar como um hiperlink e não constrói o fio de significação como é permitido nos ambientes digitais mas, ainda assim, todo o seu funcionamento está em diálogo com o digital. De acordo com Silveira (2015, p. 68), esta circulação em diferentes meios indica tanto as (não) habilidades dos sujeitos em relação aos usos da hashtag como também

apontam para seu forte potencial discursivo, pois, embora na superfície do arquivo digital as relações visíveis das hashtags remetam ao caráter hipertextual (sendo a hashtage ntendida por muitos apenas como um

\footnotetext{
4 O artigo de Chris Messina citado é intitulado como "Groups for Twitter; or A Proposal for TwitterTagChannels".

5 "technomots cliquables [...] qui permet l'organisation de l'information par le rassemblement de plusieurs messages [...]” (PAVEAU, 2013, s.p.).

6 "Il arrive de rencontrer des hashtags dans un mail ou un texto, ou sur certains sites, où ils sont intégrés linguistiquement dans les énoncés, sans leur fonctionnalité hypertextuelle. On constate donc que la forme a migré dans des contextes où elle ne fonctionne pas comme umtechnomot; elle possède alors une autre fonction, qu'il faudra déterminer" (PAVEAU, 2013, s.p.).
} 
hiperlink), elas indicam a existência de uma estrutura que relaciona de modo complexo o arquivo e memória discursiva. (ibidem, p. 69)

Partindo disso, cada uma dessas hashtags (\#SomosTodosAmarildo, \#SomosTodosMacacos,\#SomosTodosProfessores, \#SomosTodosBrasil,etc.) possuem em sua própria estrutura uma organização que as permitem funcionar sob o efeito de arquivo, compondo um "campo de documentos disponíveis e pertinentes sobre uma questão" (PÊCHEUX, [1981] 2010). Esta questão vai depender do substantivo presente no enunciado (Amarildo, Macacos, Maju, Brasil). Ao clicar em \#SomosTodosAmarildo, por exemplo, é possível encontrar reflexões acerca da violência policial, direitos humanos, segurança pública nas periferias das grandes cidades, racismo, descaso do Estado, notícias a respeito da família de Amarildo, simples relatos de indignação, convites para ajudar no projeto \#SomosTodosAmarildo, etc. Todo este grande e variado arquivo em torno da materialidade discursiva da hashtag atesta que há muitas leituras possíveis sobre um acontecimento. Deste modo, como coloca Silveira (p. 73), diferente dos textos presentes das mídias tradicionais que buscam produzir um efeito de "fechamento" do texto, as hashtags mostram que a unidade textual é um efeito imaginário. $\mathrm{O}$ arquivo reunido e possibilitado pela hashtag é constitutivamente aberto. Assim,

o modo como o discurso se textualiza na timeline, tendo a hashtag [...] como elemento integrador, permite compreender que uma hashtagé também um fato da língua, sujeita à falha e ao equívoco e ao modo como o discurso se textualiza em tais condições de produção. (SILVEIRA, 2015, p. 73)

Como as hashtags produzem "um contínuo textual, móvel, cujo caráter discursivo e ideológico joga com as palavras e a sintaxe" (SILVEIRA, p. 78) é possível observar, através delas, a língua em seu funcionamento. O jogo que ocorre por conta das lacunas, coerções e latitudes - da própria língua - (PECHEUX; GADET, 2011, p. 100) são evidentes nos usos de \#SomosTodos(...) e das demais hashtags.

Sob esta perspectiva, é importante nos atentarmos para o funcionamento sob o efeito de arquivo das hashtags, que atesta que há muitas leituras possíveis acerca do que está presente em torno do símbolo aqui estudado (\#) o que gera, justamente, gestos diferentes de leitura do arquivo (e, em nosso caso específico, das hashtags). Deste modo, conforme Pêcheux (2010, p. 58), "é esta relação entre a língua como um sistema sintático intrinsecamente passível de jogo, e a discursividade como inscrição de efeitos linguísticos materiais, que constitui o nó central de um trabalho de leitura de arquivo". Ao interpretar, confrontos e posições diferentes se colocam à tona. Assim sendo, percebe-se, no trabalho com o arquivo e, em nosso objeto específico, na relação com as hashtags, que estas disputas e diversas maneiras de ler deixam claro o fato de que o digital, as hashtags, também se constituem como um fato da língua, com lacunas específicas e sujeita à falha e ao equívoco.

Além disso, o efeito de arquivo possibilitado pelas hashtags é aberto, está em construção; não funciona sob o efeito de fechamento e estabilidade. A hashtag forma um arquivo na ideia da dispersão - assim como o discurso, que é caracterizado pela dispersão dos textos e dos sujeitos (GUIMARÃES; ORLANDI, 1985). 


\subsection{CIRCULAÇÃO}

O uso da hashtag inscreve o enunciado em uma memória metálica, a memória das máquinas, da circulação que

não se produz pela historicidade, mas por um construto técnico (televisão, computador etc.). Sua particularidade é ser horizontal (e não vertical, como a define Courtine), não havendo assim estratificação em seu processo, mas distribuição em série, na forma de adição, acúmulo: o que foi dito aqui e ali e mais além vai se juntando como se formasse uma rede de filiação e não apenas uma soma. Quantidade e não historicidade. (ORLANDI, 2006, p. 5)

\#SomosTodos(...), por ter um uso notável, por seu "recompartilhamento" em torno do mesmo que convida cada vez mais à colaboração, ao uso, ao clique vai crescendo, juntando-se em torno de muitos que se almeja ser (Amarildo, Maju, Brasil..) formando, justamente, esta "rede de filiação"através da possibilidade de circulação e acesso pela máquina na qual o mesmo é atualizado no intradiscurso. A hashtag, portanto, funciona como uma "repetição horizontal, uma re-atualização constante do sentido, presentificando a história no imediatismo da circulação, do "tempo real" (DIAS; COELHO, 2014, p. 236).

Assim, é relevante pensar nos três momentos de produção de sentido formulados por Orlandi (2001) - constituição, formulação e circulação:

1) Sua constituição, a partir da memória do dizer, fazendo intervir o contexto histórico-ideológico mais amplo;

2) Sua formulação, em condições de produção e circunstâncias de enunciação específicas e

3) Sua circulação que se dá em certa conjuntura e segundo certas condições. (ibidem, p. 09)

A hashtag, por se inscrever na memória metálica, é da ordem da circulação. Mais que a filiação do sujeito em uma rede de constituição de sentidos, neste caso, a construção de sentido se relaciona com e na atualização e circulação. O nível da constituição, pelo funcionamento da memória metálica, fica apagado, o que não quer dizer, como salienta Dias (s.d.), que o sentido não está, também, afetado e atravessado por já-ditos e pela ideologia já que, como coloca Pêcheux ([1981] 2016, p. 28), "as circulações discursivas não são nunca aleatórias".

\section{CARÁTER UNIVERSAL DA HASHTAG \#SOMOSTODOS}

Se pensarmos na estrutura de \#SomosTodos, temos a presença de um pronome indefinido (todos) e do verbo ser conjugado no plural, na tentativa de abraçar e representar o maior número de pessoas possível - ou todas. Há a tentativa de tornar homogênea e universal a campanha, a sensibilização, a torcida. 
Diante disto, para refletir acerca da universalidade da hashtag \#SomosTodos, trago Michel Pêcheux que, em Semântica e Discurso (1975 [2014, p. 117]), ao tratar do mito continuísta empírico-subjetivista o coloca como o que pretende que

a partir do sujeito concreto individual "em situação" (ligado a seus preceitos e a suas noções), se efetue um apagamento progressivo da situação por uma via que leva diretamente ao sujeito universal, situado em toda parte e lugar nenhum, e que pensa por meio de conceitos.

Deste modo, \#SomosTodosAmarildo' (e outros \#SomosTodos), pelo seu caráter e estrutura generalizante, apaga as contradições e distinções de classe existentes entre os sujeitos, convocando-os a um lugar comum, a um sentir e ser único. Promove-se uma imagem utópica de igualdade e consenso. Sob o regime da universalidade, a igualdade e a homogeneidade afirmam-se em detrimento das contradições existentes no seio social e da própria discussão e diferença de classe (média, operária, policial, do Estado) que rondam o real ocorrido com Amarildo. A subjetividade também é apagada, dando lugar ao senso comum (quase um 'Somos Todos Iguais').

Pêcheux ainda aponta que este processo de universalização ganha força em "processos de identificação que mascararam radicalmente qualquer descontinuidade espistemológica" (ibidem, p. 118). Ou seja, as descontinuidades que rompem a própria hashtag, dividindo-a e colocando em evidência a contradição estrutural existente, são silenciadas. Esta generalização e abstração segue um movimento oposto ao materialismo, desconsiderando as singularidades e diferenças constitutivas e a própria memória.

Neste sentido, sou levada a pensar na maneira como funciona a burguesia. Novamente Pêcheux (1982 [1990]), em Delimitações, Inversões e Deslocamentos, aponta que a particularidade da Revolução Burguesa, referindo-se à Revolução Francesa de 1789, foi a de "tender a absorver as diferenças rompendo as barreiras: ela universalizou as relações jurídicas no momento em que se universalizava a circulação do dinheiro, das mercadorias... e dos trabalhadores livres" (p. 10). Assim, para tornarem-se cidadãos, "os sujeitos deveriam se libertar de seus particularismos históricos" (ibidem, p. 11). O ideal de igualdade e homogeneidade já está posto desde aí e perpassa o sujeito através do discurso do Direito que representa, segundo Pecheux, "a maneira política de negar a política" (p. 11) e introduz, por meio de seu universalismo, uma "barreira política invisível" (p. 10).

Outra questão importante a respeito da hashtag \#SomosTodos(...) é que, atrelada ao seu funcionamento pela universalidade, se relaciona com a noção de língua de vento (PÊCHEUX, 1982, apud DEBRAY, 1978). A língua de vento seria, como diz Pêcheux parafraseando Debray, o discurso aparentemente sem propósito do "qualquer coisa",mas não se alimenta justamente de "qualquer coisa". Ou seja, por mais diluída, universalizante, homogênea e recompatilhada que seja, a hashtag produz sentido, silenciamentos e mobiliza a memória; é dotada de alguma força já que "uma língua de vento pode ser leve, mas pode alastrar o fogo em muitas direções" (ADORNO, 2015, p. 122). Esta força pode estar relacionada, justamente, com o que Pêcheux chama de "falsa moeda de língua de vento; turbilhão esfumaçados do "não importa o quê", destinados a chamar a atenção, desviando-a dos problemas reais" (PECHÊUX, (1981 [2016], p. 28). 


\section{MEMÓRIA E AS RELAÇÕES COM \#NINGUÉMÉHAITI}

Tomando o acontecimento, tal como definido por Pêcheux (1990, p. 17), como o "ponto de encontro entre uma atualidade e uma memória" e considerando que esta atualidade refere-se ao intradiscurso (às formulações dos sujeitos) e a memória ao interdiscurso (aos já-ditos) instaura-se, como formula Indursky (2003) - fazendo referência a Courtine (1981), o efeito de memória: "os sentidos são rememorados, atualizados, re-significados" (ibidem, p. 103). Este efeito de memória, segundo a autora, é completamente lacunar e "possibilita que os sentidos deslizem, derivem, se transformem, se re-signifiquem” (p. 104).

Já a memória discursiva é definida por Pêcheux (1999) como:

aquilo que, face a um texto que surge como acontecimento a ler, vem reestabelecer os implícitos (quer dizer, mais tecnicamente, os préconstruídos, elementos citados e relatados, discursos transversos, etc.) de que sua leitura necessita: a condição legível em relação ao próprio legível. (p. 52)

Estes implícitos estariam, em um discurso, "ausentes pela sua presença" e, de acordo com Courtine (1981, p. 53) a "noção de memória discursiva diz respeito à existência histórica do enunciado no seio de práticas discursivas, reguladas pelo aparelho ideológico".

Ao lado da retomada e da repetição, ocorrem os deslizamentos de sentido, os quais são responsáveis pela reorganização da memória. De acordo com Indursky (idem, p. 107), esses movimentos, ao mesmo tempo em que conduzem um retorno da memória, estabelecem uma ruptura com a rede de formulações a qual o enunciado está relacionado. O sentido, portanto, deriva e torna-se outro. Isto, segundo a autora, estaria na base do acontecimento discursivo que vem "perturbar a memória" (PECHEUX, 1999). Um acontecimento discursivo

rompe com a inscrição na ordem da repetibilidade, mas não tem como apagar a memória, a ressonância do sentido-outro. Dito de outra forma: um acontecimento discursivo rompe com a ordem do repetível, instaurando um novo sentido, mas não consegue produzir $o$ "esquecimento" do sentido-outro, que o precede. Quando ocorre uma ruptura com a repetibilidade, uma nova ordem de repetibilidade se instaura, a qual é responsável pela reorganização da memória, pela organização de uma nova estrutura vertical, a qual necessariamente mantém relações com a estrutura precedente, com a qual rompeu. (p. 107-08)

Desse modo, após a grande circulação de diferentes hashtags \#SomosTodos(...) (as quais produzem sentidos distintos umas das outras) repercutiu nas redes, em outubro de 2016, \#Ninguém é Haiti. A hashtag, resultado de uma charge produzida pelo cartunista Miguel Villalba Sánchez, servia como apoio ao Haiti após ser atingido pelo furacão Mattew. O Jornal O Globo publicou a seguinte fala do autor da charge "Quase800 mortos no Haiti, mas ninguém coloca fotos de perfil especiais no Facebook nem slogans para as vítimas do furacão Matthew". \#NinguéméHaiti "perturba a memória" e faz ressoar 
\#SomosTodos(...) por conta da memória discursiva e pela sua própria estrutura (presença de um pronome indefinido e do verbo ser).

Considerando os jogos de força na memória, propostos por Pêcheux (1999, p. 53), que funcionam sob o choque do acontecimento, há:

- um jogo de força que visa manter uma regularização pré-existente com os implícitos que ela veicula, confortá-la como "boa forma", estabilização parafrástica negociando a integração do acontecimento, até absorvê-lo e eventualmente dissolvê-lo; - mas também, ao contrário, o jogo de força de uma "desregulação" que vem perturbar a rede dos "implícitos".

\#NinguémÉHaiti se encaixa neste segundo jogo, já que é um acontecimento que desequilibra a memória e a rede de implícitos vista em \#SomosTodos(...), instaurando uma desregularização no discurso de igualdade e homogeneidade.

Como este trabalho com a memória pressupõe o deslizamento de sentidos, é pertinente trazer Orlandi (2012), que aborda a necessidade de dar luz à historicidade uma vez que o foco da análise não se sustenta apenas nos fatos "objetivos", na cronologia ou no que está fora, mas sim no "fora dentro" (ibidem, p. 13). Por esta via, a autora aponta para a noção de "efeito metafórico" (PECHÊUX, 1990) que seria, justamente, o que permite o deslizar de sentidos, a deriva. Por meio desta deriva, desta ruptura na repetição, provoca-se um efeito sobre o sentido que se está produzindo e sobre aquele do qual ele desliza.

Esta movimentação na rede de constituição de sentidos, fortemente ligada à historicidade, também se relaciona com as condições de produção, com a memória discursiva e com a ideologia sendo, portanto, denominada pela autora como "sentidos em fuga". Fuga, aqui, não deve ser entendida como o que foge, mas sim como aquilo que "corre, desliza, vai, ressoa, ecoa, arrebanha sentidos em movimento, em outro lugar" (ORLANDI, 2012, p. 19). Sentidos em fuga, portanto, são mais do que deriva, pressupõem uma relação forte com a polissemia, ou seja, com a "pluralidade de movimentos de sentido num mesmo objeto simbólico" (ibidem, p. 25) e, assim, se constituem, nas palavras da autora, como uma "explosão, uma desorganização produzida pelo movimento".

Através da forma (\#SomosTodos) da hashtag aqui analisada, é possível observar alguns movimentos de deriva. Pensaremos, primeiramente, em três hashtags: \#SomosTodosAmarildo, \#SomosTodosMacacos e \#SomosTodosMaju. \#SomosTodosAmarildo, como já exposto, é uma hashtag que carrega um forte sentido de justiça pela vida (e família) de Amarildo, morador da periferia do Rio de Janeiro. Já no ano seguinte (2014), circulou fortemente nas redes sociais a hashtag \#SomosTodosMacacos - que ganhou evidência depois que, em uma partida de futebol na Espanha, uma banana foi arremessada no jogador Daniel Alves. Mais tarde, \#SomosTodosMaju entrou nos tópicos mais comentados do twitter em conseqüência de comentários racistas que a jornalista da Rede Globo Maju Coutinho sofreu nas redes sociais. 
Estas três hashtags se encontram por fazerem ecoar na memória questões acerca do racimo. No entanto, mesmo neste encontro, há a contradição, o conflito, pois o que cada uma delas suscita a respeito da questão racial é diferente. \#SomosTodosAmarildo denuncia a ausência do Estado, traz a questão da (in)justiça de uma maneira muito forte, além de dar voz a muitos outros Amarildos, homens negros, de periferia, desaparecidos nas favelas do Rio de Janeiro durante execuções arbitrárias da polícia militar. \#SomosTodosMacacos e \#SomosTodosMaju produzem um outro efeito sobre o racismo, já que não focam na relação entre preconceito racial e periferia, violência policial e justiça social. E é aí que se encontra o movimento de deriva. Há, nestas duas últimas hashtags, uma denúncia ao racismo sofrido por pessoas famosas e bem-sucedidas amparadas, neste caso, pelo Estado e pelo público. ${ }^{7}$

Já em 2016, \#SomosTodosOlímpicos foi mote da transmissão dos Jogos Olímpicos pela Rede Globo de Comunicação, que pretendia buscar "o envolvimento dos brasileiros com o chamado espírito olímpico"8. Em um dos vídeos institucionais desta campanha, além de imagens de diferentes atletas praticando seus respectivos esportes, uma voz ecoa 'Somos Todos Preparação, Somos TodosSuperação, Somos Todos Olímpicos'.A hashtag, neste caso, se inscreve em uma formação discursiva completamente diferente das anteriores. Além de não tratar da questão racial, também não é (re)compartilhada para dar apoio a alguém diante de alguma situação considerada injusta. O sentido de unidade, o ser todos, está na alegria de superar os obstáculos - assim como os atletas - e viver um momento olímpico (transmitido pela TV). O sentido de denúncia deriva para festa, alegria, marketing.

Depois de todos estes usos, quando nos deparamos com \#NinguémÉHaiti temos esta "explosão que desestabiliza e produz movimento desordenado" (ORLANDI, 2012, p. 25). A formação foi derivando até encontrar o inverso de sua estrutura, de somos todos para ninguém é. Por meio deste ninguém, escorre o silenciamento pelo qual o Haiti sofre - da mídia e do próprio Estado.

Além disso, é possível estabelecer uma relação entre \#NinguémÉHaiti e \#SomosTodosAmarildo. Assim como o Haiti, Amarildo também se constitui como negro, pobre, morador de uma comunidade carente do Rio de Janeiro e mais uma vítima da polícia dentre tantas outras que permanecem abandonadas e esquecidas. Amarildo e Haiti se encontram, portanto, através do descaso e da invisibilidade que sofrem e da qual são apenas “mais um". \#NinguéméHaiti' ressignifica \#SomosTodosAmarildo, o coloca em outro lugar, questiona a universalização posta neste "ser todos". E é por esta perspectiva que se percebe os sentidos em fuga levantados por \#NinguémÉHaiti - mais que produzir uma deriva, esta hashtag gerou uma desordem no sentido de igualdade e homogeneidade já estabelecido por \#SomosTodos. \#NinguémÉ vem lembrar a indefinição ou ausência (invertida) que também existe em \#SomosTodos, significando pelo seu avesso. E é justamente por isso que propusemos pensar nas semelhanças entre Amarildo e Haiti, uma vez que a estrutura derivou para tantos lugares (torcidas para candidatos de Reality

\footnotetext{
${ }^{7}$ É importante registrar que sabemos que há muitas outras hashtags (e movimentos) que denunciam o racismo e que trazem à tona o Movimento Negro e os Movimentos de Mulheres Negras. No entanto, o nosso recorte de análise, neste artigo, se restringe apenas às relações entre Amarildo e Haiti por meio de uma hashtag, não permitindo que outras questões sejam abordadas com maior profundidade.

8 Informação retirada da Publicação da Direção Geral de Negócios da Rede Globo, disponível em: http://negocios8.redeglobo.com.br/BIP/Lists/BIP\%20PDF\%20Instance/BIP 609.pdf; $\quad$ acesso em 28/06/207.
} 
Shows, apoio a figuras políticas, campanhas publicitárias) e encontrou um ponto comum no seu avesso. O Haiti é aqui, o Haiti não é aqui: este refrão demonstra a tensão entre o mesmo e o diferente, possibilitada pelos deslizes de sentido que pensamos aqui, no encontro entre Amarildo e Haiti.

\section{REFERÊNCIAS}

ADORNO de OLIVEIRA, G. (2015). Discursos sobre o eu na composição autoral dos vlogs. Tese. Doutorado em Linguística. Campinas: Universidade Estadual de Campinas.

COURTINE, J.-J. [1981]. Análise do discurso político. O discurso comunista endereçado aos cristãos. São Carlos: Edufscar, 2009.

DIAS, C.; COELHO, A. V de vinagre: a produção de imagens humorísticas sobre as manifestações brasileiras de 2013 nas redes sociais. Em. PATTI, A.R. et. al. (Orgs.). Textecendo discursos na contemporaneidade. São Carlos: Pedro \& João, 2012.

DIAS, C. A tecnologia como condição de produção do conhecimento na sociedade contemporânea: redes, memória e circulação. Em: FLORES, G. et. al. (Orgs.). Análise do Discurso em Rede: cultura e mídia. São Paulo: Pontes, 2015. p. 279-290.

GUIMARÃES, E.; ORLANDI, E.P. (1985). Unidade e dispersão: uma questão do texto e do sujeito. Em: ORLANDI, E. (Orga.). Discurso e Leitura. São Paulo: Cortez; Campinas: Ed. da Unicamp, 1988.

MESSINA, Chris. Groups for Twitter: or a proposal for twitter tag channels. 2007. Disponível em: http://factoryjoe.com/blog/2007/08/25/groups-for-twitter-or-a-proposalfor-twitter-tag-channels/. Acesso em: 10 de maio 2017.

ORLANDI, E. A fuga de sentidos: efeitos da polissemia e do silêncio. Em: Carrozza, G.; SILVA, T.D. da (Orgs.). Sujeito, sociedade, sentidos. Campinas: RG, 2012.

Discurso e textualidade. Campinas: Pontes, 2006.

PAVEAU, M.-A. "Hashtag", Technologies discursives. 2013. [Carnet de recherche]. Disponível em: http://technodiscours.hypotheses.org/488. Acesso em 10 maio de 2017.

PÊCHEUX, M. Abertura do Colóquio. Em: CONEIN, B. et. al. Materialidades Discursivas. Trad. Bras. Campinas: Editora da Unicamp, 2016.

Semântica e discurso: uma crítica à afirmação do óbvio. Trad. Bras. $4^{\text {a }}$. ed. Campinas: Ed. da Unicamp, 2014.

. Ler o arquivo hoje. Em: ORLANDI, E.P. (Org.). Gestos de leitura: da história no discurso. Campinas: Editora da Unicamp, 2010. 
Papel da memória. Em: ACHARD, P. et. al. Papel da memória. Trad. Bras. Campinas: Pontes, 1999.

Delimitações, Inversões, Deslocamentos. Trad. Bras. Cadernos de Estudos Linguísticos, 19, p. 7-24, Campinas, IEL/UNICAMP, 1990.

O discurso: estrutura ou acontecimento. Campinas: Pontes, 1990.

SILVEIRA, Juliana da. Análise discursiva da hashtag \#onagagné: entre a estrutura e o acontecimento. Tese. Doutorado em Letras, Estudos Linguísticos, Universidade Estadual de Maringá, Maringá, 2015.

\section{Para citar este texto:}

PEREIRA, Deborah. De Amarildo ao Haiti: reflexões sobre universalidade e memória em torno de duas hashtags. Entremeios [Revista de Estudos do Discurso, ISSN 2179-3514, on-line, www.entremeios.inf.br], Seção Estudos, Programa de Pós-Graduação em Ciências da Linguagem (PPGCL), Universidade do Vale do Sapucaí (UNIVÁS), Pouso Alegre (MG), vol. 16, p. 121-131, jan. - jun. 2018.

DOI: http://dx.doi.org/10.20337/ISSN2179-3514revistaENTREMEIOSvol16pagina121a131 